\title{
Lesions of pemphigus vulgaris on irradiated skin
}

\author{
L. Aguado, M. Marquina, M. Pretel, G. Ruiz-Carrillo and A. España \\ Department of Dermatology, University Clinic of Navarra, Pamplona, Spain
}

Correspondence: Dr Leyre Aguado Gil, Department of Dermatology, Clínica Universitaria de Navarra, Avenida Pio XII, 36, 31008 Pamplona, Navarra, Spain.

E-mail: laguado@unav.es

\section{SUMMARY}

Pemphigus vulgaris (PV) is an autoimmune blistering disease produced by IgG autoantibodies against desmoglein (Dsg)3. Lesions on the skin and mucosa can, in rare cases, be induced by radiotherapy. We report a patient with a history of microprolactinoma and PV, who had only oral lesions from the beginning of her illness but 2 months after treatment with radiotherapy for a breast neoplasia, developed skin lesions limited to the irradiated area. Over the following few months, she also developed autoantibodies against Dsg1.

Pemphigus vulgaris (PV) is a blistering disease produced by IgG autoantibodies, which bind mainly to desmoglein (Dsg)3. It can be induced by many triggers including drugs, burns, nutritional factors, herpes virus, contact dermatitis, emotional stress and ultraviolet radiation. ${ }^{1}$ Although rare, ionizing radiation treatment can also induce $\mathrm{PV} .{ }^{2-7}$

\section{REPORT}

A 39-year-old woman presented to our centre in 1999 with a 7-month history of amenorrhoea. She reported no headache, visual field reduction or spontaneous galactorrhoea. Laboratory investigations found a raised serum prolactin level (106.3 $\mathrm{ng} / \mathrm{mL}$; normal range 1.4-24). Magnetic resonance imaging (MRI) of the brain using paramagnetic contrast revealed a hypophyseal microadenoma. The patient was started on treatment with a dopaminergic agonist (cabergoline).

In 2000, patient developed dysphagia, dysphonia and erosions in the mouth. Histological examination of a biopsy taken from an erosion revealed an intraepidermal suprabasilar blister with acantholysis. Direct immunofluorescence (DIF) using total IgG (IgGT) showed intense deposits of IgG and C3 on the cell surface of the keratinocytes. Indirect immunofluorescence (IIF) found circulating antiepithelial cell surface IgG (titre 1 : 80). Using ELISA (MBL Naka-ku Nagoya, Japan), anti-Dsg3 antibodies (48 U/mL; normal range 0 - 20) were found, but there were no anti-Dsg1 antibodies. Fibroscopy revealed lesions on the pharynx and larynx. The patient was diagnosed with a mucosaldominant PV. A few days after beginning treatment, she also presented lesions on the 
back, right ear and nose (the number of cutaneous lesions was $<5$, so her illness was still considered mucosal-dominant PV). ${ }^{8}$

Over the next 6 years, the patient had occasional oral lesions (Fig. 1a) but no cutaneous lesions. In 2002, she developed new oral lesions while she was being treated with azathioprine and low-dose corticosteroids. Azathioprine was changed to mycophenolic acid. In 2003, oral corticosteroids were discontinued, and in 2005, mycophenolic acid was discontinued. The patient was advised to use topical triamcinolone acetonide if she developed oral lesions.

In 2006, the patient was diagnosed with an intraductal carcinoma type II of the breast (negative for p53 and C-erb-2, 100\% positive for oestrogen and progesterone, positive for E-cadherin; Van Nuys Prognostic Index 7; TisN0M0). She underwent conservative surgery and radiotherapy for 2 months. Fractions of $2 \mathrm{~Gy}$, using $6 \mathrm{MeV}$ photons, were given daily until a total dose of $50 \mathrm{~Gy}$ was reached. The scar and the surgical bed were further treated using a direct field of electrons of $9 \mathrm{MeV}$, daily fractions of $2 \mathrm{~Gy}$, until an additional dose of 16 Gy had been delivered to this site. During the radiotherapy, she continued being treated with cabergoline.

Two months after finishing the radiotherapy, skin lesions suggestive of PV appeared on the irradiated breast (Fig. 1b), and the patient also presented oral lesions. IIF revealed no circulating antiepithelial cell surface IgGT. ELISA detected borderline levels of antiDsg3 antibodies (19.18 U/mL) and was also positive for anti-Dsg1 antibodies (26.96 $\mathrm{U} / \mathrm{mL}$; normal range 0-20) (Table 1). One month later, the patient was still negative for circulating antiepithelial cell surface IgGT, anti-Dsg3 antibody levels were still borderline $(15.60 \mathrm{U} / \mathrm{mL})$ and anti-Dsg1 antibodies were again positive $(22.20 \mathrm{U} / \mathrm{mL})$ (Table 1).

Currently, the patient continues to develop occasional lesions in the mouth and on the irradiated breast. She is negative for circulating antiepithelial cell surface IgGT, antiDsg3 antibodies are borderline (15.38) and antiDsg1 antibodies are negative (Table 1). Restarting systemic treatment has not been suggested because of her history of breast neoplasia, and because the oral and the breast lesions are well controlled with topical corticosteroids.

PV can be induced by the administration of radiotherapy. ${ }^{2-7}$ In previous reports, radiotherapy was used for the treatment of various neoplasms, ${ }^{4-6}$ and the time interval between the radiotherapy and the onset of the cutaneous lesions varied from a few days to $>1$ year. $^{4}$

The explanation for this relationship between PV and radiotherapy is unclear. The ionizing radiation may alter the antigenicity of the surface of the keratinocytes, thus changing the immunoreactivity of the desmogleins or unmasking certain epidermal antigens. ${ }^{4,5}$ An increase in the concentration of the antibodies against the basement membrane may also be produced by radiotherapy. ${ }^{5}$ The existence in almost all cases of an underlying neoplasm raises the question as to the role that cancer and its treatment may play in the induction of PV. ${ }^{4,5}$ The immune disturbance produced by the neoplasm may contribute to development of $\mathrm{PV}^{2}$ One hypothesis maintains that the cause may be a crossover between tumour and keratinocyte antigens. Another hypothesis suggests that 
an alteration in the regulation of the cell cycle may be the origin of both the tumoral proliferation and the defective elimination of auto-reactive lymphocyte clones.

In our patient, the fact that for 6 years she had lesions exclusively on the oral mucosa, and that lesions appeared on the skin only after radiotherapy and then only on the radiated site, indicates that the radiotherapy itself induced the new lesions. This is further supported by the observation that over the months after the radiotherapy, the patient presented anti-Dsg1 antibodies. This was probably due to the 'epitopespreading' phenomenon; ${ }^{9}$ the tissue damage produced by the radiotherapy caused the release and exposure of a previously 'sequestered' antigen, leading to a secondary autoimmune response against this newly released antigen.

Our patient had a hypophyseal prolactin-producing microadenoma, which probably favoured the growth of the breast neoplasm. Increases in prolactin may be a contributing factor for the appearance of the PV, as an increase in prolactin has been associated with the onset of various autoimmune illnesses. ${ }^{10}$

The microadenoma was diagnosed with the help of MRI using paramagnetic contrast. A diagnostic process using an imaging agent can be the initial primer for the immune system, unleashing an immune response. However, we have found no published cases suggesting a relationship between pemphigus and the previous use of paramagnetic contrast.

During the radiotherapy, our patient continued being treated with cabergoline. An immunological interaction between the radiation treatment and the immune dysregulation produced by the dopaminergic agonist is possible.

We present this case to show that radiotherapy can induce lesions of PV. The case is also interesting because for a few months after receiving radiotherapy, our patient also presented autoantibodies against Dsg1.

\section{REFERENCES}

1. Orion E, Barzilay D, Brenner S. Pemphigus vulgaris induced by diazinon and sun exposure. Dermatology 2000; 201: 378-9.

2. Crovato F, Desirello G, Nazzari G, De Marchi R. Linear pemphigus vulgaris after X-ray irradiation. Dermatologica 1989; 179: 135-6.

3. David M, Feuerman EJ. Induction of pemphigus by X-ray irradiation. Clin Exp Dermatol 1987; 12: 197-9.

4. Delaporte E, Piette F, Bergoend H. Pemphigus vulgaris induced by radiotherapy (In French). Ann Dermatol Venereol 1991; 118: 447-51.

5. Girolomoni G, Mazzone E, Zambruno G. Pemphigus vulgaris following cobalt therapy for bronchial carcinoma. Dermatologica 1989; 178: 37-8.

6. Mseddi M, Bouassida S, Khemakhem $M$ et al. Radiotherapy-induced pemphigus: a case report (In French). Cancer Radiother 2005; 9: 96-8.

7. Low GJ, Keeling JH. Ionizing radiation-induced pemphigus. Case presentations and literature review. Arch Dermatol 1990; 126: 1319-23. 
8. Amagai M, Tsunoda K, Zillikens $\mathrm{D}$ et al. The clinical phenotype of pemphigus is defined by the anti-desmoglein autoantibody profile. 1 Am Acad Dermatol 1999; 40: 167-70.

9. Chan LS, Vanderlugt CJ, Hashimoto $\mathrm{T}$ et al. Epitope spreading: lessons from autoimmune skin diseases.1 Invest Dermatol 1998; 110: 103-9.

10. De Bellis A, Bizzarro A, Pivonello R et al. Prolactin and autoimmunity. Pituitary 2005; 8: 25-30. 

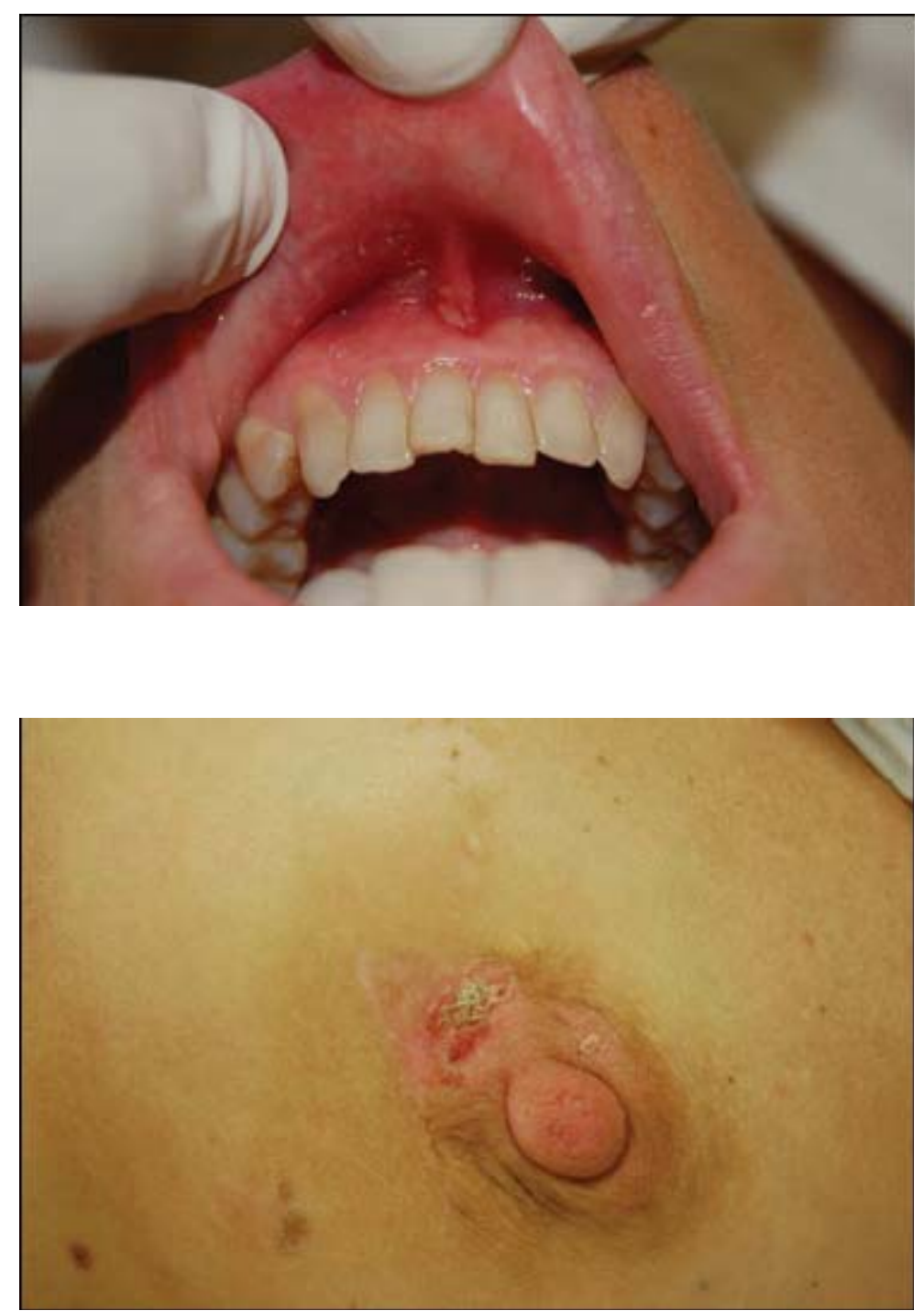

Figure 1. Lesions (a) in the mouth and (b) on the breast. 
Table 1. Autoantibodies present the patient

\begin{tabular}{|l|c|c|c|c|c|}
\hline Autoantibody & At start of illness & $\begin{array}{c}\text { March } \\
\mathbf{2 0 0 6}\end{array}$ & August 2006 & $\begin{array}{c}\text { September } \\
\mathbf{2 0 0 6}\end{array}$ & November 2006 \\
\hline $\begin{array}{l}\text { Antiepithelial cell } \\
\text { surface IgG }\end{array}$ & $\begin{array}{c}\text { Positive (titre } \\
1: 80)\end{array}$ & Negative & Negative & Negative & Negative \\
\hline $\begin{array}{l}\text { Anti-Dsg3 } \\
\text { antibodies }\end{array}$ & $\begin{array}{c}\text { Positive }(48 \mathrm{U} / \\
\mathrm{mL})\end{array}$ & Negative & $\begin{array}{c}\text { Borderline }(9.18 \\
\mathrm{U} / \mathrm{mL})\end{array}$ & $\begin{array}{c}\text { Borderline }(5.60 \\
\mathrm{U} / \mathrm{mL})\end{array}$ & $\begin{array}{c}\text { Borderline } \\
(15.38 \mathrm{U} / \mathrm{mL})\end{array}$ \\
\hline $\begin{array}{l}\text { Anti-Dsg1 } \\
\text { antibodies }\end{array}$ & Negative & Negative & $\begin{array}{c}\text { Positive }(26.96 \\
\mathrm{U} / \mathrm{mL})\end{array}$ & $\begin{array}{c}\text { Positive }(22.20 \\
\mathrm{U} / \mathrm{mL})\end{array}$ & Negative \\
\hline
\end{tabular}

Dsg, desmoglein. Normal range for anti-Dsg1 and anti-Dsg3 antibodies: 0-20 U/mL. The patient received radiotherapy from 8 March to 27 April 2006. 